\title{
Title: The point of diminishing returns: An examination of expanding Vancouver's Insite
}

\author{
Martin A. Andresen ${ }^{1,2}$ and Ehsan Jozaghi ${ }^{2}$ \\ Pre-publication version 2012 \\ Published in \\ Urban Studies, 49(16) 3531-35
}

To link to this article: $\underline{\text { https://doi.org/10.1177/0042098012443865 }}$

${ }^{1}$ Institute for Canadian Urban Research Studies, Simon Fraser University, 8888 University Drive, Burnaby, British Columbia, V5A 1S6, Canada. E-mail: andresen@sfu.ca

${ }^{2}$ School of Criminology, Simon Fraser University, 8888 University Drive, Burnaby, British Columbia, V5A 1S6,

Canada. E-mail: eja2@sfu.ca.

\section{Funding Statement}

This research received no specific grant from any funding agency in the public, commercial or not-for-profit sectors.

\section{Acknowledgements}

The authors are grateful to Katrina Zubko, Sonya Powell, and three anonymous referees for their comments and suggestions that made this a much more focused and clear paper.

\section{Notes}

1. Estimates of the IDU population range from 4700 (Remis et al., 1998) to 8000 (Harvard et al., 2008).

2. The Dr Peter Centre in Vancouver provides a "Harm Reduction Room" for the supervised injection of street drugs for HIV-positive programme participants. This facility opened one year before Insite and is a small operation supervising approximately 50 injections per month (Kru"si et al., 2009).

3. These are other parameters in the analysis, shown in Table 1.

4. Vancouver Coastal Health uses both the Maximally Assisted Therapy (MAT) program and the Seek and Treat for Optimal Prevention (STOP) of HIV/AIDS team in order to increase Highly Active Antiretroviral Therapy (HAART) adherence in the DTES IDU population. 


\title{
The point of diminishing returns: An examination of expanding Vancouver's Insite
}

\begin{abstract}
North America's only government-sanctioned supervised injection facility, Insite, has been subjected to substantial research. This research has found evidence for numerous public health benefits: decreased risky injection behaviour, decreased fatal overdoses, increased probability of initiating and maintaining addiction treatment, and costeffectiveness. To date, a small number of costing studies have emerged with none of them investigating Insite expansions. Such an analysis is reported in this paper and it is found that, based on benefit-cost ratios, Insite should be expanded. However, this expansion is dependent on altering injection drug user behaviour outside Insite.
\end{abstract}




\section{Introduction}

The history of Vancouver's Downtown Eastside (DTES) began more than 100 years ago as part of the city's commercial core of finance, retailing and culture. With office towers only blocks away that were among the highest in the British Empire, this area of Vancouver was lively and dynamic (Barnes and Sutton, 2009). Beginning in the mid- $20^{\text {th }}$ century, the DTES became a haven for the most marginalised populations in the city, eventually including Canada's lowest income per capita census tract (Barnes and Sutton, 2009). However, low income is not the only form of deprivation in this area of the city (Ley and Smith, 2000).

The DTES is home to single-room occupancy hotels, bars, pawn shops, prostitution and a high concentration of injection drug users (IDUs). The injection of illicit drugs (heroin, cocaine, etc.) is associated with life threatening diseases such as HIV/AIDS and hepatitis B/C. This is a serious public health issue because there are an estimated 5000 IDUs living in the DTES (McClean, 2002; Kerr et al., 2005a). ${ }^{1}$ Should state health care intervene and provide programmes and paraphernalia encouraging healthier methods of this drug use such as needles/syringes, needle cleaning kits, condoms, etc.?

Over the past two decades, needle exchange programmes have become an increasingly popular public health programme repeatedly showing net public health benefits (Kaplan and O'Keefe, 1993; Jacobs et al., 1999; Laufer, 2001). Despite the success of these programmes, the state provision of drug-related materials has its critics. As outlined by Lurie et al. (1993), one of the most topical debates regarding the state provision of drugrelated materials (needle exchange programmes, specifically) is whether or not making drug use 'less costly' will lead to expanded drug use for current users and the recruitment of new IDUs. There is no scientific evidence to support these concerns (Des Jarlais et al., 1992; Lurie et al., 1993; Vlahov and Junge, 1998; Watters et al., 1994).

A more recent development regarding injection drug use is the (medically) supervised injection facility (SIF). In SIFs, IDUs bring in previously obtained illicit drugs, are provided with injection equipment and a place to inject. Although medical staff at the facility cannot perform the injection, they may help IDUs prepare the injection and provide medical attention afterwards if necessary (Kerr et al., 2005b; Wood, Tyndall, Zhang et al., 2006).

On 22 September 2003, North America's first and only government-sanctioned SIF (Insite), opened its doors in Vancouver, British Columbia, Canada. ${ }^{2}$ For many SIFs, including Insite in Vancouver, exemptions from provincial/state and/or federal law may be required for operation. In the case of Vancouver, an exemption from Canada's Controlled Drugs and Substances Act was necessary for its operation (Vancouver Coastal Health, 2007), allowing users to consume illicit drugs at Insite without arrest. Despite this exemption, a number of legal victories and scientific evidence supporting public health benefits, the Federal Government of Canada attempted to close down Insite.

The British Columbia Supreme Court ruled that Insite should remain open because the facility is under the realm of health care provision and, therefore, provincial jurisdiction (PHS Community Services v. Attorney General of Canada, BCSC, 2008). Despite this ruling, the federal government pursued their case to the Supreme Court of Canada (Canada [Attorney General] vs PHS Community Services Society, 2011 SCC 44). On 30 September 2011, the Supreme Court of Canada ruled in favour of Insite remaining open. Moreover, the ruling included criteria for future expansions of similar SIFs. In any application for expansion, authorities must consider whether or not denying an expansion would cause decreases in the state of public health while simultaneously considering public safety concerns such as crime. Currently, city staff in Toronto are expected to provide a report on the pros and cons of SIFs in early 2012 (Ogilvie, 2011) while Quebec is accepting proposals from Montreal and Quebec City (Se'guin and Peritz, 2011). See Small (2010) for a history of the legal issues surrounding Insite.

Not surprisingly, a significant amount of research has been undertaken and published regarding the impact of Insite. Since the opening of Insite, research has shown that: There is no evidence of increased drug trafficking 
or crime related to drug use (Wood, Tyndall, Lai et al., 2006); IDUs that use Insite engage in fewer risky injection behaviours (Kerr et al., 2005b); the facility is shown to be cost-effective, providing a net savings to the health care system (Bayoumi and Zaric, 2008; Andresen and Boyd, 2010); the fatal overdose rate is significantly lower post-Insite (Marshall et al., 2011); and IDUs that regularly use Insite have an increased probability of initiating and maintaining addiction treatment (DeBeck et al., 2011).

At this stage for Insite, an obvious question to pose is: Should it be expanded? In this paper, we contribute to the literature on Insite through an investigation of expanding Insite within Vancouver's DTES. We use a simple, but realistic, mathematical model to predict the number of new HIV infections. Our objective is to perform a cost-benefit analysis for each successive expansion of the SIF component of Insite. These expansions include 24-hour operations (instead of 18-hour) and the establishment of other same-sized facilities. We calculate benefit-cost ratios at the margin (for each incremental expansion) and for the operation as a whole (all facilities).

\section{Previous Cost-Benefit and Cost-effectiveness Studies of Insite}

Bayoumi and Zaric (2008) published the first economic analysis of the SIF portion of Insite. They use a complex dynamic compartmental simulation model for the City of Vancouver as a whole and projected new HIV and hepatitis $\mathrm{C}$ infections over a 10-year time horizon with and without Insite. In their baseline model, Bayoumi and Zaric (2008) estimate that 1191 new HIV and 54 new hepatitis C cases are averted. Therefore, considering a simple average over the 10 years, Bayoumi and Zaric (2008) predict that the presence (and use) of Insite averts 120 new cases of HIV each year.

Considering the lifetime cost of a new HIV infection at \$210, 555 (Pinkerton, 2010; Albert et al., 1998), these averted cases lead to an annual savings of $\$ 25$ million, a benefit-cost ratio of 16.84, assuming a $\$ 1.5$ million cost of operations for the SIF portion of Insite (Andresen and Boyd, 2010). With this empirical support for cost savings, it is surprising that there is any debate over whether Insite should remain open or not (see, for example, Small, 2010). However, these numbers are quite simply too good to be true. In all of British Columbia between 1999 and 2003, the five years before Insite opened, there were approximately 140 new cases of HIV related to IDUs (BC Centre for Disease Control, 2005, 2009). Therefore, the Bayoumi and Zaric (2008) model predicted that Insite prevented 80 per cent of all new IDU cases of HIV each year for all of British Columbia - approximately 5 per cent of all injections in Vancouver's DTES take place within Insite. Bayoumi and Zaric's (2008) model is complex, dynamic and considers a score of variables, but the results are quite simply not believable.

In a commentary on Bayoumi and Zaric (2008), Des Jarlais et al. (2008) used a simple method to estimate that Insite prevents 20-30 new cases of HIV each year. Considering a \$210, 555 lifetime cost of a new HIV infection and a \$1.5 million operational cost of Insite, Des Jarlais et al. (2008) estimate benefit-cost ratios that range from 2.81 to 4.21 . This is a more reasonable range that still provides significant support for the continued operation of Insite as a SIF. Andresen and Boyd (2010) undertake a cost-benefit and costeffectiveness analysis of Insite, but only consider averted cases of HIV. They consider four mathematical models used in the needle exchange evaluation literature, varying parameter values in a sensitivity analysis.

Andresen and Boyd's (2010) results indicate, depending on the model, that 19-57 new cases of HIV are averted, an average of 35 cases averted each year. This leads to benefit-cost ratios ranging from 1.94 to 5.8, an average of 3.56. These results are in line with those of Des Jarlais et al. (2008) and support the continued operation of the SIF. Pinkerton $(2010,2011)$ performed the two remaining cost studies of Insite. Both analyses are based on Kaplan's needle circulation theory (Kaplan and O'Keefe, 1993; Kaplan, 1995) and show that Insite as a whole (SIF, needle exchange programme, etc.) is extremely cost-effective, but that the SIF alone contributes very little: 83.5 new HIV cases are averted each year, with 2.8 attributed to the SIF (Pinkerton, 2010); 4-8 new HIV cases are averted each year (Pinkerton, 2011). Considering the values used earlier, this leads to benefit-cost ratios of 0.37 (Pinkerton, 2010) and 0.8 (Pinkerton, 2011), with the latter benefit-cost ratio based on the mid point. Clearly, these latter results indicate that Insite should not continue its 
SIF activities if costs are to determine that choice. An obvious question emerges: why are Pinkerton's (2010, 2011) results so different from the previous results? The answer is simple. Pinkerton $(2010,2011)$ does not consider behavioural changes of IDUs with regard to needle-sharing in his models. As stated earlier, research shows that Insite users have a significantly lower rate of needle-sharing than non-Insite users (Kerr et al., 2005b). Bayoumi and Zaric (2008) and Andresen and Boyd (2010) incorporate this into their models.

Considering Andresen and Boyd's (2010) most realistic model based on data from the BC Centre for Disease Control (Jacobs et al., 1999), new cases of HIV averted fall to 9, almost within the upper range provided by Pinkerton (2011), without the behavioural change in needle-sharing. Overall, these four studies indicate that Insite is cost-saving for society, but for different reasons: Bayoumi and Zaric (2008) and Andresen and Boyd (2010) attribute the cost-savings to the SIF and Pinkerton $(2010,2011)$ attributes the cost-savings to the needle exchange programme. Because the SIF within Insite is the contentious aspect of Insite, we focus our analysis on the SIF. We consider this reasonable because these two functions of Insite are separable and distinguishable.

Hence, one component of Insite may be shut down while the other remains open. Moreover, it is the SIF component of Insite that may be expanded, not only in Vancouver, but in Toronto, Montreal and Quebec City. Model, Methods and Data Modelling a facility such as Insite must be done carefully in order for the results to be credible. There are two possibilities for Insite expansions. First, Insite may be open for more hours and, secondly, new facilities may be opened. The first possibility is limited because it restricts Insite's expansion to 33 per cent: 18 to 24 hours per day. Because of this limitation, we consider longer hours of the current facility as well as the establishment of more facilities. These changes are implemented in the Jacobs et al. (1999) model, described in detail later, through modification of the rate of needle-sharing. Because this model is static, this is the only credible impact Insite will have on new HIV infections because none of the injections within Insite are shared injections. When we consider additional facilities, we make the mathematical model 'dynamic' by sequentially changing (decreasing) the rate of needle sharing. It should be noted that over time Insite would impact the proportion of IDUs that are HIV+ as well as the percentage of needles cleaned before use. ${ }^{3}$ Thus, only considering changes in the rate of needle-sharing underestimates the impact of Insite expansions.

With this discussion in mind, the choice of model for an analysis of Insite's performance with regard to new HIV infections averted must be done carefully. Considering the predicted new cases of HIV with and without the establishment of Insite and the data from the BC Centre for Disease Control (2009), the Jacobs et al. (1999) model adapted by Andresen and Boyd (2010) is arguably the best choice, although its estimates for total new HIV cases per year are still high. We also choose to employ the behaviour change incorporated by Bayoumi and Zaric (2008) and Andresen and Boyd (2010) because of its empirical evidence (Kerr et al., 2005b; Bravo et al., 2009).

Although Andresen and Boyd (2010) err on the side of caution and employ an odds ratio of 0.60 , we choose to use the point estimate of 0.30 used by Bayoumi and Zaric (2008), estimated by Kerr et al. (2005b).

The Jacobs et al. (1999) model is estimated as follows:

$$
\text { New HIV infections }=I N s d\left[1-(1-q t)^{\mathrm{m}}\right]
$$

where, $I$ is the proportion of IDUs that are HIV-; $N$ is the number of needles in circulation; $s$ is the rate of needle-sharing; $d$ is the percentage of needles not cleaned; $q$ is the proportion of IDUs that are HIV+; $t$ is the probability of an HIV infection from a single injection; and $m$ is the average number of sharing partners.

The values for these parameters (and their sources) are shown in Table 1. In order to estimate the impact of Insite on new cases of HIV infections, the rate of needle-sharing variable is manipulated: no shared injections are performed within Insite and, because of the behavioural change regarding needle sharing, there are fewer shared injections outside Insite, but only for those who are users of Insite. 


\section{<Insert Table 1 About Here>}

In its original formulation that stipulates a needle cleaning rate of 83 per cent and an average of 1.38 sharing partners, the Jacobs et al. (1999) model predicts 165 new cases of HIV per year in the DTES. However, over the most recent seven years, there has been an average of 108 new cases of HIV in the IDU population for the entire province of British Columbia. This is not a realistic baseline. The DTES is most definitely overrepresented in British Columbia with regard to the number of new HIV cases in the IDU population, but this prediction using the Jacobs et al. (1999) model is problematic.

Hence, we modify the parameter values for this model. The number of HIV+/-, the number of needles in circulation, the rate of needle-sharing and the probability of HIV infection from a single injection are all well documented in the literature and supported by research in Vancouver's DTES (see Table 1). However, the percentage of needles not cleaned and the average number of sharing partners are not supported with recent or Vancouver context data. Hence, we modify these parameter values (downward) to bring the Jacobs et al. (1999) model predictions in line with BC Centre for Disease Control (2009) data. We decrease the percentage of needles not cleaned to 12.5 and the average number of sharing partners per shared injection to 1 , the obvious lower bound - further manipulations do little to alter the results discussed later. These changes bring the predicted number of new HIV cases per year in the DTES IDU population to a reasonable value. Moreover, we believe these are reasonable parameter modifications. The IDU population is likely to be involved in less high risk behaviour than 12 years ago because of all the campaigns regarding cleaner injections.

The baseline Jacobs et al. (1999) model now predicts 88 new cases of HIV in the DTES IDU population. This is 20 cases fewer than in the population of IDUs in British Columbia as a whole, a far more realistic number. The use of the behaviour change on needle-sharing variable deserves special attention. If a second Insite is established, further behavioural changes occur if and only if new IDUs become users of Insite. If only current users of Insite use the new SIF, simply performing more of their injections at Insite, no further behavioural changes can be assumed. Because of complications with the behavioural change variable we model a number of scenarios. The first scenario considers expansions of Insite that only consider 'one' behavioural change. In this scenario, only the current users of Insite use Insite expansions. This is considered to be one-third of the IDU population in the DTES (Tyndall et al., 2003). With the continued expansion of Insite under this scenario, the impact of behavioural change becomes incrementally less because fewer injections outside Insite have the potential for shared needles.

The second scenario considers attracting another one third of the IDU population in the DTES and then continues as with the first scenario. This subsequent one-third is chosen to simplify the analysis and because the first Insite attracted one-third of the IDU population in Vancouver's DTES. And the third scenario considers attracting the final one-third of the IDU population in the DTES and continues as with the previous two scenarios. Of course, in reality, each expansion of Insite is unlikely immediately to attract a further onethird of the DTES IDU population. Rather, the current users are expected to use Insite more frequently with the attraction of some new users. Modelling such scenarios, however, would not only be a monotonous task, but a monotonous read with little insight gained relative to the general results. Hence, the results of the modelling and any cost savings should be considered as upper and lower bounds for the impact of Insite's expansion.

The range of the lifetime cost-savings from averted cases of HIV is large in magnitude ranging from US\$50, 000 (Kaplan and O'Keefe, 1993), to US\$200,000 (Chen et al., 2006; Holtgrave and Pinkerton, 1997; Pinkerton and Holtgrave, 1998), to more than US $\$ 250,000$ when considering the very successful multidrug combinations Highly Active Antiretroviral Therapy (HAART). The HAART treatments are highly effective, but rather intensive. Because of this, treatment initiations and adherence rates to HAART tend to be low among the IDU population (Lert and Kazatchkine, 2007). Laufer (2001) states that IDUs are less likely to take full advantage

of the medical system. ${ }^{4}$ Hence, the US $\$ 250,000$ figure may be too high when considering the impact of Insite. Because of this, Andresen and Boyd (2010) used CDN\$150,000 in their modelling. However, the most recent research in this area (Pinkerton, 2010, 2011) used CDN\$210,555, that is based on the work of Albert et 
al. (1998). Because of Pinkerton's expertise in this research area, we use the CDN\$210,555 figure. We acknowledge that the calculated cost-savings of Insite are an underestimate of the overall cost-savings. Our model does not incorporate: any growth of the IDU population, similar to that of Bayoumi and Zaric (2008); new secondary HIV infections (Lurie and Drucker, 1997; Marshall et al., 2009); and the reduction of other harms such as cellulitis, subcutaneous abscesses, endocarditis and other soft-tissue infections (Lurie et al., 1998). Thus, the calculated cost-savings are an underestimate of the true cost-savings.

The total operational costs of Insite are \$3 million (Health Canada, 2008; Pinkerton, 2010, 2011). This includes the SIF, addiction counselling and case management, the provision of primary healthcare, public health screening (immunisations and diagnostics), addiction and housing services, education and peer counselling. As outlined by Andresen and Boyd (2010), the annual operational cost of the SIF portion of Insite is \$1.5 million (CTV News, 2008, an interview of Dr Thomas Kerr, Principal Investigator, Insite). Although Pinkerton (2010) used the $\$ 3$ million figure in his analysis of Insite as a whole, we use the $\$ 1.5$ million figure because we only consider the SIF. When considering the expansion of Insite from 18 to 24 hours in the modelling, this increases the operational cost of Insite to \$2 million, a one-third increase in the hours of operation. This is an overestimate of increased costs because the fixed costs of Insite (lease, permits, etc.) will not increase with increased hours of operation. Lastly, we undertake a sensitivity analysis of our model, considering different initial needle-sharing rates. We follow Andresen and Boyd (2010) and use 20 and 40 per cent initial needle-sharing rates in addition to the baseline of 30 per cent.

\section{Results}

The results of the mathematical modelling are presented in Tables 2-4. These tables are organised based on what portion of the IDU population experiences behavioural change because of their use of the SIF. In these tables, expansions of Insite are continued until the maximum impact on decreased sharing has occurred for each behavioural change. Table 2 shows the results for one-third of the IDU population exhibiting behavioural change, operating as a comparison with the results of Andresen and Boyd (2010). The baseline result, Insite operational for 18 hours, predicts that 22 new cases of HIV are averted per year. This is 5 less than the baseline result using the same model in Andresen and Boyd (2010), because of different parameter values. Regardless, the benefit-cost ratio is higher than in Andresen and Boyd (2010), 3.09 rather than 2.74, because we use a greater cost-savings from an averted case of HIV.

The results for expansions of Insite, the marginal HIV infections averted and benefit-cost ratios, are very low in magnitude. With an expansion to 24 hours of operation, there are no new HIV infections averted and subsequent expansions of Insite reveal only 1 or 2 additional new HIV infections averted. This results in marginal benefit-cost ratios of 0.11 and 0.21 respectively. Considering the total impact of 'Insite', an expansion to two Insites operating 24 hours can be justified on a cost basis with a benefit-cost ratio of 1.26 - subsequent expansions bring the benefit-cost ratio below unity.

\section{<Insert Table 2 About Here>}

The results for two-thirds of the IDU population experiencing behavioural change (Table 3) are similar. With the recruitment of new IDUs into the Insite culture and corresponding behavioural change, there are 45 new HIV infections averted per year, a benefit-cost ratio of 2.37. Similar to the results in Table 2, subsequent expansions of Insite are limited to 1 or 2 new HIV infections prevented per year, marginal benefit-cost ratios of 0.11 and 0.21 respectively. Overall, the total impact of 'Insite' indicates an expansion to five Insites operating 24 hours with a benefit-cost ratio of 1.05 .

\section{<Insert Table 3 About Here>}

Lastly, the results for Insite expanding to all IDUs in Vancouver's DTES exhibiting behavioural change are presented in Table 4. As with the previous results, the primary impact on new cases of HIV averted is the initial expansion of Insite. With the third expansion of Insite expected to draw in the final one-third of the IDU 
population, a total of 67 new HIV infections are prevented each year, a benefit-cost ratio of 2.35. And, as with the results in Tables 2 and 3, subsequent expansions result in 1 or 2 marginal HIV infections averted, benefitcost ratios of 0.11 and 0.21 respectively. Again, considering the total impact of 'Insite', an expansion to eight Insites operating 24 hours can be justified on a cost basis with a benefit-cost ratio of 1.00.

The sensitivity analysis, reported in the parentheses in Tables $2-4$, shows that these conclusions are not too sensitive to changes in the initial needle-sharing rate. Even with our baseline model that more accurately predicts the number of new HIV infections in Vancouver's DTES, Insite (for both 18 and 24 hours of operation) costs are always outweighed by the benefits. The only difference that emerges from the sensitivity analysis is how many new SIFs should be established. However, the impact is small: The number of new SIFs justified using benefit-cost ratios most often increases/decreases by one and sometimes two.

\section{Discussion}

\section{<Insert Table 4 About Here>}

SIFs provide numerous public health benefits. In the case of Insite, there has been no evidence of increased drug trafficking or crime related to drug use (Wood, Tyndall, Lai et al., 2006); IDUs that use Insite engage in risky injection behaviours less often (Kerr et al., 2005b); the facility provides a net savings to the health care system (Bayoumi and Zaric, 2008; Andresen and Boyd, 2010); the fatal overdose rate is significantly lower post-Insite (Marshall et al., 2011); and IDUs that regularly use Insite have an increased probability of initiating and maintaining addiction treatment (DeBeck et al., 2011). Although some argue that the provision of public health care services such as Insite needs no economic rationale for existence (Small, 2010), in these times of increasingly precarious fiscal realities the various options for harm reduction must be considered. To date, two studies show Insite as an economic benefit to public health care.

However, the work of Pinkerton $(2010,2011)$ calls the economic rationale for the SIF portion of Insite into question. As discussed earlier, the primary difference between the work of Bayoumi and Zaric (2008) and Andresen and Boyd (2010), compared with that of Pinkerton $(2010,2011)$ is the consideration of behaviour change. This is shown to be an important aspect of the results in the current analysis as well. Through the use of the Jacobs et al. (1999) mathematical model, we have shown that Insite is indeed cost-saving. Our model is similar to that used by Andresen and Boyd (2010) that also shows cost-savings, but our output is in line with known numbers of new HIV infections in the IDU population.

We are able to show that the number of new HIV infections averted, and the associated cost-savings, is more than enough to cover the costs of Insite's operation. Therefore, if one accepts the scientific research regarding behavioural changes (decreased risky behaviours such as needle-sharing) in the IDU population, there is a strong case for maintaining Insite. The expansion of Insite is not as straightforward. The first expansion of Insite is to have the facility open 24 hours a day. As shown in Table 2, such an expansion leads to no further averted HIV infections, a marginal benefit-cost ratio of zero. Additionally, all expansions of Insite that do not consider additional behavioural changes in the IDU population only averted one or two new HIV infections per year, 0.11 and 0.21 benefit-cost ratios respectively. These latter numbers are more in line with those of Pinkerton (2010, 2011) than those of Bayoumi and Zaric (2008) and Andresen and Boyd (2010).

However, if there are additional behavioural changes in the IDU population then the marginal number of new HIV infections prevented increases linearly and the benefit-cost ratios remain relatively constant at 2.35, on average. Clearly, from a marginal perspective, Insite must recruit new users from the IDU population for Insite expansions to be cost-saving. With Insite currently operating at capacity, such recruitment is highly probable. In fact, Petrar et al. (2007) find that the primary reasons for not using Insite are travel time, hours of operation and waiting times. The latter two are clearly interrelated and can be dealt with through expansions of both operation times and the facility itself. The former indicates that the current location of Insite should not simply be expanded to facilitate more injections. Rather, any increases in capacity, aside from increased hours of operation, must carefully consider location. 
There is very little research regarding the spatial movements of the IDU population in Vancouver's DTES. However, this literature (two published articles that we are aware of at this time) strongly supports the need for a consideration of location for any SIF expansions. Fast et al., studying young IDUs (16-26 years), find that IDUs carve out relatively 'safe' geographical niches within the downtown drug scene and employ spatial tactics aimed at reducing harm (Fast et al., 2010, p. 57). This behaviour leads to self-imposed geographical segregation of different groups of IDUs within Vancouver's downtown. Consequently, there are areas some IDUs purposely avoid. Moreover, Reddon et al. (2011) find that distance from Insite is a significant factor for not using the SIF. Because of this result, Reddon et al. (2011) state that any efforts to expand Insite should focus on increasing the number of SIFs and their geographical coverage.

With this importance of location and the need to attract new users for marginal cost savings, research must be conducted before any expansions are taken place. Specifically, the IDU population itself must be consulted. Just as the establishment of fire stations minimises the distance to any one of their potential 'customers', so must the establishment of future Insites. This becomes increasingly complex if multiple sites are to be established, particularly if these sites are to be established sequentially. A second Insite must be placed where there is demand, far enough away from the current Insite to attract new users from the IDU population, and considering any potential future expansions. Clearly, any expansions for Vancouver's SIF are complex.

The question of how many Insites to open depends on how many new users of Insite are expected. Is it realistic to think that, if enough facilities are opened, all injections will be performed at an Insite location? Probably not. Thus, opening the equivalent of eight Insites would not prove to be cost-saving despite the results of the model shown in Table 4. More realistically, there will be an increase in the number of IDUs using these facilities along the lines of the results shown in Table 3. With these benefit-cost ratios in mind, there is justification for as many as five Insites. This number should be considered a lower bound because the benefits are underestimated in the current analysis.

Additionally, this analysis assumes that the costs of establishing new Insites are linear. If developers of future Insites consider economies of scale by building larger facilities, there may be justification for the provision of even more Insite facilities to help address this all too common innercity problem. As with any analysis, ours is not without limitations. First, we only consider new HIV infections as a basis for our cost-benefit analysis. However, as already noted, Insite is associated with a number of other positive outcomes that reduce mortality and morbidity. The difficulty is attempting to quantify positive outcomes and assigning dollar values. Because of this limitation, the case for Insite expansion is stronger than presented here only considering new HIV infections.

Secondly, although 'dynamic' in the sense that our method considers the establishment of successive SIFs, our model is static. Changed injection behaviour and decreases in new HIV infections will impact the level of HIV incidence over time and, potentially, the cleaning of needles and the number of sharing partners. Regardless, the results presented here show support for the expansion of SIFs in Vancouver's DTES. Policy-makers must take care when choosing the location of future expansions in order to maximise their benefits. And we expect future facility expansions in other contexts/municipalities also to bring in public health benefits that exceed costs. 


\section{References}

Albert, T., Williams, G., Legowski, B. and Remis, R. (1998) The economic burden of HIV/AIDS in Canada. Study No. H-02, Canadian Policy Research Networks, Ottawa, ON.

Andresen, M. A. and Boyd, N. T. (2010) A cost-benefit and cost-effectiveness analysis of Vancouver's supervised injection facility, International Journal of Drug Policy, 21, pp. 70-76.

Barnes, T. and Sutton, T. (2009) Situating the new economy: contingencies of regeneration and dislocation in Vancouver's inner city, Urban Studies, 46, pp. 1247-1269.

Bayoumi, A. M. and Zaric, G. S. (2008) The cost-effectiveness of Vancouver's supervised injection facility, Canadian Medical Association Journal, 179, pp. 1143-1151.

BC Centre for Disease Control (2005) STD/AIDS: 2005 annual report. BC Centre for Disease Control, Vancouver, BC.

BC Centre for Disease Control (2009) HIV and AIDS: annual supplement report 2009. BC Centre for Disease Control, Vancouver, BC.

Bravo, M. J., Royuela, L., Fuente, L. de la, Brugal, M. T. et al. (2009) Use of supervised injection facilities and injection risk behaviours among young drug injectors, Addiction, 104, pp. 614-619.

Buxton, J. (2008) Vancouver drug use epidemiology: site report for the Canadian community epidemiology network on drug use. Canadian Community Epidemiology Network on Drug Use, Canadian Centre on Substance Abuse, Ottawa, ON.

Chen, R. Y., Accortt, N. A., Westfall, A. O., Mugavero, M. J. et al. (2006) Distribution of health care expenditures for HIV-infected patients, Clinical Infectious Diseases, 42, pp.1003-1010.

CTV News (2008) Experts table findings on drug injection site. Vancouver, Canada (http://www.ctv.ca; accessed 12 April 2008).

DeBeck, K., Kerr, T., Bird, L., Zhang, R. et al. (2011) Injection drug use cessation and use of North America's first medically supervised safer injecting facility, Drug and Alcohol Dependence, 113, pp. 172-176.

Des Jarlais, D. C., Arasteh, K. and Hagan, H. (2008) Evaluating Vancouver's supervised injection facility: data and dollars, symbols and ethics, Canadian Medical Association Journal, 179, pp. 1105-1106.

Des Jarlais, D. C., Friedman, S. R., Choopanya, K., Vanichsenis, S. et al. (1992) International epidemiology among injecting drug users, AIDS, 6, pp. 1053-1068.

Des Jarlais, D. C., Marmor, M., Paone, D., Titus, S. et al. (1996) HIV incidence among injecting drug users in New York City syringe-exchange programmes, Lancet, 348, pp. 987-991.

Fast, D., Shoveller, J., Shannon, K. and Kerr, T. (2010) Safety and danger in downtown Vancouver: understandings of place among young people entrenched in an urban drug scene, Health \& Place, 16, pp. 5160 .

Harvard, S. S., Hill, W. D. and Buxton, J. A. (2008) Harm reduction product distribution in British Columbia, Canadian Journal of Public Health, 99, pp. 446-450. 
Health Canada (2008) Expert panel report on supervised injection site released. Health Canada press release, Ottawa, Canada (http://www.hc-sc.gc.ca/ahcasc/media/nr-cp/2008/200857e.html; accessed 23 April 2008).

Holtgrave, D. R. and Pinkerton, S. D. (1997) Updates of cost of illness and quality of life estimates for use in economic evaluations of HIV prevention programs, Journal of Acquired Immune Deficiency Syndromes and Human Retrovirology, 16, pp. 55-61.

Holtgrave, D. R., Pinkerton, S. D., Jones, T. S., Lurie, P. et al. (1998) Cost and cost-effectiveness of increasing access to sterile syringes and needles as an HIV prevention intervention in the United States, Journal of Acquired Immune Deficiency Syndromes and Human Retrovirology, 18(Suppl. 1), pp. S133-S138.

Jacobs, P., Calder, P., Taylor, M., Houston, S. et al. (1999) Cost effectiveness of Streetworks' needle exchange program of Edmonton, Canadian Journal of Public Health, 90, pp. 168-171.

Kaplan, E. H. (1995) Economic analysis of needle exchange, AIDS, 9, pp. 1113-1119.

Kaplan, E. H. and O'Keefe, E. (1993) Let the needles do the talking! Evaluating the New Haven needle exchange, Interfaces, 23, pp. 7-26.

Kerr, T., Tyndall, M., Li, K., Montaner, J. S. and Wood, E. (2005a) Potential use of safer injecting facilities among injection drug users in Vancouver's downtown eastside, Canadian Medical Association Journal, 169, pp. 759-763.

Kerr, T., Tyndall, M., Li, K., Montaner, J. S. and Wood, E. (2005b) Safer injection facility use and syringe sharing in injection drug users, Lancet, 366, pp. 316-318.

Kru“si, A., Small, W., Wood, E. and Kerr, T. (2009) An integrated supervised injecting program within a care facility for HIV-positive individuals: a qualitative evaluation, AIDS Care, 21, pp. 638-644.

Laufer, F. N. (2001) Cost-effectiveness of syringe exchanges as an HIV prevention strategy, Journal of Acquired Immune Deficiency Syndromes, 28, pp. 273-278.

Lert, F. and Kazatchkine, M. D. (2007) Antiretroviral HIV treatment and care for injecting drug users: an evidence-based overview, International Journal of Drug Policy, 18, pp. 255-261.

Ley, D. and Smith, H. (2000) Relations between deprivation and immigrant groups in large Canadian cities, Urban Studies, 37, pp. 37-62.

Lurie, P. and Drucker, E. (1997) An opportunity lost: HIV infections associated with a lack of a national needle-exchange programme in the USA, Lancet, 349, pp. 604-608.

Lurie, P., Gorsky, R., Jones, T. S. and Shomphe, L. (1998) An economic analysis of needle exchange and pharmacy-based programs to increase sterile syringe availability for injection drug users, Journal of Acquired Immune Deficiency Syndromes and Human Retrovirology, 18, pp. S126-S132.

Lurie, P., Reingold, A. L., Bowser, B., Chen, D. et al. (1993) The public health impact of needle exchange programs in the United States and abroad: summary, conclusions and recommendations. School of Public Health, University of California, Berkeley, CA.

Marshall, B. D. L., Milloy, M.-J., Wood, E., Montaner, J. S. G. et al. (2011) Reduction in overdose mortality after opening of North America's first medically supervised safer injecting facility: a retrospective population based study, Lancet, 377, pp. 1429-1437. 
Marshall, B. D. L., Wood, E., Zhang, R., Tyndall, M. W. et al. (2009) Condom use among injection drug users accessing a supervised injection facility, Sexually Transmitted Infections, 85, pp. 121-126.

McClean, M. E. (2002) Vancouver drug use epidemiology-2001: Vancouver and BC site report for the Canadian community epidemiology network on drug use. Richmond Health Board, Vancouver, BC.

Ogilvie, M. (2011) Safe injection site would work in T.O., study suggests: preliminary version of long-awaited report says city would benefit from up to three clinics, Toronto Star, 2 November, p. A1.

Petrar, S., Kerr, T., Tyndall, M. W., Zhang, R. et al. (2007) Injection drug users' perceptions regarding use of a medically supervised safer injection facility, Addictive Behaviors, 32, pp. 1088-1093.

Pinkerton, S. D. (2010) Is Vancouver Canada's supervised injection facility cost-saving?, Addiction, 105, pp. $1429-1436$.

Pinkerton, S. D. (2011) How many HIV infections are prevented by Vancouver Canada's supervised injection facility?, International Journal of Drug Policy, 22, pp. 179-183.

Pinkerton, S. D. and Holtgrave, D. R. (1998) Assessing the cost-effectiveness of HIV prevention interventions: a primer, in: D. R. Holtgrave (Ed.) Handbook of Economic Evaluation of HIV Programs, pp. 33-43. New York: Plenum.

Reddon, H., Wood, E., Tyndall, M., Lai, C. et al. (2011) Use of North America's first medically supervised safer injecting facility among HIV positive injection drug users, AIDS Education and Prevention, 23, pp. 412422.

Remis, R. S., Leclerc, P., Routledge, R., Taylor, C. et al. (1998) Consortium to characterize injection drug users in Canada (Montreal, Toronto, and Vancouver). Division of HIV/AIDS Epidemiology Research, Bureau of HI/AIDS and STD, Laboratory Centre for Disease Control, Health Canada, Ottawa, ON.

Se'guin, R. and Peritz, I. (2011) Quebec opens door to setting up safe-injection sites, Globe and Mail, 11 October.

Siegel, J. E., Weinstein, M. C. and Fineberg, H. V. (1991) Bleach programs for preventing AIDS among IV drug users: modelling the impact of HIV prevalence, American Journal of Public Health, 81, pp. 1273-1279.

Small, D. (2010) An appeal to humanity: legal victory in favour of North America's only supervised injection facility, Insite, Harm Reduction Journal, 7, p. 23.

Tyndall, M. W., Currie, S., Spittal, P., Li, K. et al. (2003) Intensive injection cocaine use as the primary risk factor in the Vancouver HIV-1 epidemic, AIDS, 17, pp. 887-893.

Tyndall, M. W., Wood, E., Zhang, R., Lai, C. et al. (2006) HIV seroprevalence along participants of a supervised injection facility in Vancouver, Canada, Harm Reduction Journal, 3, pp. 36-40.

Vancouver Coastal Health (2007) Insite - supervised injection site. Health Services, Vancouver Coastal Health, Vancouver, Canada (http://www.vch.ca/sis/; accessed 1 December 2007).

Vlahov, D. and Junge, B. (1998) The role of needle exchange programs in HIV prevention, Public Health Reports, 113(Suppl. 1), pp. 75-80.

Watters, J., Estilo, M., Clark, G. and Lorvick, J. (1994) Syringe and needle exchange as HIV/AIDS prevention for injection drug users, Journal of the American Medical Association, 271, pp. 115-120. 
Wood, E., Kerr, T., Small, W., Li, K. et al. (2004) Changes in public order after the opening of a medically supervised safer injecting facility for illicit injection drug users, Canadian Medical Association Journal, 171, pp. 731-734.

Wood, E., Tyndall, M. W., Lai, C., Montaner, J. S. G. et al. (2006) Impact of a medically supervised safer injecting facility on drug dealing and other drug-related crime, Substance Abuse Treatment, Prevention, and Policy, 1, article 13.

Wood, E., Tyndall, M. W., Spittal, P. M., Li, K. et al. (2001) Unsafe injection practices in a cohort of injection drug users in Vancouver: could safer injecting rooms help?, Canadian Medical Association Journal, 165, pp. 405-410.

Wood, E., Tyndall, M. W., Zhang, R., Stoltz, J. et al. (2006) Attendance of supervised injecting facilities and use of detoxification services, New England Journal of Medicine, 354, pp. 2512 - 2514. 
Table 1. Values and Sources for Parameters in Jacobs et al. (1999) model

\begin{tabular}{|c|c|c|}
\hline Parameter & Value & Source \\
\hline Proportion of IDUs HIV- $(I)$ & $77.46 \%$ & Petrar et al. (2007), Tyndall et al. (2006b) \\
\hline Number of needles in circulation $(N)$ & 2 million & McClean (2002), Buxton (2008) \\
\hline Rate of needle sharing $(s)$ & $30 \%$ & $\begin{array}{l}\text { Kaplan and O'Keefe (1993), Laufer } \\
\text { (2001), Jacobs et al. (1999), Des Jarlais et } \\
\text { al. (1996), Siegel, Weinstein, \& Fineberg } \\
\text { (1991), Holtgrave et al. (1998), Kerr et al. } \\
\text { (2005a), Wood et al. (2001) }\end{array}$ \\
\hline Percent of needles not cleaned $(d)$ & $\begin{array}{c}17 \% \\
\text { (12.5\% used } \\
\text { in the } \\
\text { analysis) }\end{array}$ & $\begin{array}{l}\text { Kaplan and O'Keefe (1993), Jacobs et al. } \\
\text { (1999) }\end{array}$ \\
\hline Proportion of IDUs HIV+ $(q)$ & $22.54 \%$ & Petrar et al. (2007), Tyndall et al. (2006b) \\
\hline $\begin{array}{l}\text { Probability of HIV infection from } \\
\text { single injection }(t)\end{array}$ & $0.67 \%$ & Kaplan and O'Keefe (1993) \\
\hline Number of sharing partners $(m)$ & $\begin{array}{l}1.38 \\
\text { (1 used in } \\
\text { the } \\
\text { analysis) }\end{array}$ & Jacobs et al. (1999) \\
\hline
\end{tabular}


Table 2. New HIV Infections Averted, Behavioural Change for One-Third of the IDU Population

\begin{tabular}{|c|c|c|c|c|c|}
\hline & Sharing Rate & $\begin{array}{c}\text { Marginal HIV } \\
\text { Infections } \\
\text { Averted }\end{array}$ & $\begin{array}{c}\text { Total HIV } \\
\text { Infections } \\
\text { Averted }\end{array}$ & $\begin{array}{c}\text { Marginal } \\
\text { Benefit-Cost } \\
\text { Ratio }\end{array}$ & $\begin{array}{c}\text { Total Benefit- } \\
\text { Cost Ratio }\end{array}$ \\
\hline Insite -18 Hours & $\begin{array}{c}22.54 \\
(15.03,30.06)\end{array}$ & $\begin{array}{c}22 \\
(15,29)\end{array}$ & $\begin{array}{c}22 \\
(15,29)\end{array}$ & $\begin{array}{c}3.09 \\
(2.11,4.07)\end{array}$ & $\begin{array}{c}3.09 \\
(2.11,4.07)\end{array}$ \\
\hline Insite -24 Hours & $\begin{array}{c}22.39 \\
(14.93,29.85)\end{array}$ & $\begin{array}{c}0 \\
(0,1)\end{array}$ & $\begin{array}{c}22 \\
(15,30)\end{array}$ & $\begin{array}{c}0.00 \\
(0.00,0.11)\end{array}$ & $\begin{array}{c}2.32 \\
(1.58,3.16)\end{array}$ \\
\hline 2 Insites - 24 Hours & $\begin{array}{c}21.78 \\
(14.52,29.04)\end{array}$ & $\begin{array}{c}2 \\
(1,2)\end{array}$ & $\begin{array}{c}24 \\
(16,32)\end{array}$ & $\begin{array}{c}0.21 \\
(0.11,0.21)\end{array}$ & $\begin{array}{c}1.26 \\
(0.84,1.68)\end{array}$ \\
\hline 3 Insites - 24 Hours & $\begin{array}{c}21.17 \\
(14.11,28.23)\end{array}$ & $\begin{array}{c}2 \\
(1,2)\end{array}$ & $\begin{array}{c}26 \\
(17,34)\end{array}$ & $\begin{array}{c}0.21 \\
(0.11,0.21)\end{array}$ & $\begin{array}{c}0.91 \\
(0.60,1.19)\end{array}$ \\
\hline 4 Insites -24 Hours & $\begin{array}{c}20.56 \\
(13.71,27.41)\end{array}$ & $\begin{array}{c}2 \\
(1,3)\end{array}$ & $\begin{array}{c}28 \\
(18,37)\end{array}$ & $\begin{array}{c}0.21 \\
(0.11,0.32)\end{array}$ & $\begin{array}{c}0.74 \\
(0.47,0.57)\end{array}$ \\
\hline 5 Insites -24 Hours & $\begin{array}{c}20.00 \\
(13.33,26.67)\end{array}$ & $\begin{array}{c}1 \\
(2,2)\end{array}$ & $\begin{array}{c}29 \\
(20,39)\end{array}$ & $\begin{array}{c}0.11 \\
(0.21,0.21)\end{array}$ & $\begin{array}{c}0.61 \\
(0.42,0.82)\end{array}$ \\
\hline
\end{tabular}

Note: The numbers in parentheses represent the results of the sensitivity analysis: (20 per cent sharing rate, 40 per cent sharing rate). 
Table 3. New HIV Infections Averted, Behavioural Change for Two-Thirds of the IDU Population

\begin{tabular}{|c|c|c|c|c|c|}
\hline & Sharing Rate & $\begin{array}{l}\text { Marginal HIV } \\
\text { Infections Averted }\end{array}$ & $\begin{array}{c}\text { Total HIV } \\
\text { Infections } \\
\text { Averted }\end{array}$ & $\begin{array}{l}\text { Marginal Benefit- } \\
\qquad \text { Cost Ratio }\end{array}$ & $\begin{array}{l}\text { Total Benefit- } \\
\text { Cost Ratio }\end{array}$ \\
\hline $\begin{array}{l}2 \text { Insites - } 24 \\
\text { Hours }\end{array}$ & $\begin{array}{c}14.78 \\
(9.85,19.71)\end{array}$ & $\begin{array}{c}45 \\
(30,59)\end{array}$ & $\begin{array}{c}45 \\
(30,59)\end{array}$ & $\begin{array}{c}2.37 \\
(1.58,3.11)\end{array}$ & $\begin{array}{c}2.37 \\
(1.58,3.11)\end{array}$ \\
\hline $\begin{array}{l}3 \text { Insites - } 24 \\
\text { Hours }\end{array}$ & $\begin{array}{c}14.17 \\
(9.45,18.89)\end{array}$ & $\begin{array}{c}1 \\
(1,3)\end{array}$ & $\begin{array}{c}46 \\
(31,62)\end{array}$ & $\begin{array}{c}0.11 \\
(0.11,0.32)\end{array}$ & $\begin{array}{c}1.61 \\
(1.09,2.18)\end{array}$ \\
\hline $\begin{array}{l}4 \text { Insites - } 24 \\
\text { Hours }\end{array}$ & $\begin{array}{c}13.56 \\
(9.04,18.08)\end{array}$ & $\begin{array}{c}2 \\
(1,2)\end{array}$ & $\begin{array}{c}48 \\
(32,64)\end{array}$ & $\begin{array}{c}0.21 \\
(0.11,0.21)\end{array}$ & $\begin{array}{c}1.26 \\
(0.84,1.68)\end{array}$ \\
\hline $\begin{array}{l}5 \text { Insites - } 24 \\
\text { Hours }\end{array}$ & $\begin{array}{c}12.95 \\
(8.63,17.27)\end{array}$ & $\begin{array}{c}2 \\
(1,2)\end{array}$ & $\begin{array}{c}50 \\
(33,66)\end{array}$ & $\begin{array}{c}0.21 \\
(0.11,0.21)\end{array}$ & $\begin{array}{c}1.05 \\
(0.69,1.39)\end{array}$ \\
\hline $\begin{array}{l}6 \text { Insites }-24 \\
\text { Hours }\end{array}$ & $\begin{array}{c}12.34 \\
(8.23,16.45)\end{array}$ & $\begin{array}{c}2 \\
(1,3)\end{array}$ & $\begin{array}{c}52 \\
(34,69)\end{array}$ & $\begin{array}{c}0.21 \\
(0.11,0.32)\end{array}$ & $\begin{array}{c}0.91 \\
(0.60,1.21)\end{array}$ \\
\hline $\begin{array}{l}7 \text { Insites - } 24 \\
\text { Hours }\end{array}$ & $\begin{array}{c}11.73 \\
(7.82,15.64)\end{array}$ & $\begin{array}{c}1 \\
(2,2)\end{array}$ & $\begin{array}{c}53 \\
(36,71)\end{array}$ & $\begin{array}{c}0.11 \\
(0.21,0.21)\end{array}$ & $\begin{array}{c}0.80 \\
(0.54,1.07)\end{array}$ \\
\hline $\begin{array}{l}8 \text { Insites - } 24 \\
\text { Hours }\end{array}$ & $\begin{array}{c}11.12 \\
(7.41,14.83)\end{array}$ & $\begin{array}{c}2 \\
(1,3)\end{array}$ & $\begin{array}{c}55 \\
(37,74)\end{array}$ & $\begin{array}{c}0.21 \\
(0.11,0.32)\end{array}$ & $\begin{array}{c}0.72 \\
(0.49,0.97)\end{array}$ \\
\hline $\begin{array}{l}9 \text { Insites - } 24 \\
\text { Hours }\end{array}$ & $\begin{array}{c}10.51 \\
(7.01,14.01)\end{array}$ & $\begin{array}{c}2 \\
(1,2)\end{array}$ & $\begin{array}{c}57 \\
(38,76)\end{array}$ & $\begin{array}{c}0.21 \\
(0.11,0.21)\end{array}$ & $\begin{array}{c}0.67 \\
(0.44,0.89)\end{array}$ \\
\hline $\begin{array}{l}10 \text { Insites - } \\
24 \text { Hours }\end{array}$ & $\begin{array}{c}10.00 \\
(6.67,13.33)\end{array}$ & $\begin{array}{c}1 \\
(1,2)\end{array}$ & $\begin{array}{c}58 \\
(39,78)\end{array}$ & $\begin{array}{c}0.11 \\
(0.11,0.21)\end{array}$ & $\begin{array}{c}0.61 \\
(0.41,0.82)\end{array}$ \\
\hline
\end{tabular}

Note: The numbers in parentheses represent the results of the sensitivity analysis: (20 per cent sharing rate, 40 per cent sharing rate). 
Table 4. New HIV Infections Averted, Behavioural Change for the Entire IDU Population

\begin{tabular}{|c|c|c|c|c|c|}
\hline & Sharing Rate & $\begin{array}{c}\text { Marginal HIV } \\
\text { Infections Averted }\end{array}$ & $\begin{array}{c}\text { Total HIV } \\
\text { Infections Averted }\end{array}$ & $\begin{array}{c}\text { Marginal Benefit- } \\
\text { Cost Ratio }\end{array}$ & $\begin{array}{c}\text { Total Benefit-Cost } \\
\text { Ratio }\end{array}$ \\
\hline 3 Insites - 24 Hours & $\begin{array}{c}7.17 \\
(4.78,9.56)\end{array}$ & $\begin{array}{c}67 \\
(45,89)\end{array}$ & $\begin{array}{c}67 \\
(45,89)\end{array}$ & $\begin{array}{c}2.35 \\
(1.58,3.12)\end{array}$ & $\begin{array}{c}2.35 \\
(1.58,3.12)\end{array}$ \\
\hline 4 Insites -24 Hours & $\begin{array}{c}6.56 \\
(4.37,8.75)\end{array}$ & $\begin{array}{c}2 \\
(1,2)\end{array}$ & $\begin{array}{c}69 \\
(46,91)\end{array}$ & $\begin{array}{c}0.21 \\
(0.11,0.21)\end{array}$ & $\begin{array}{c}1.82 \\
(1.21,2.40)\end{array}$ \\
\hline 5 Insites -24 Hours & $\begin{array}{c}5.95 \\
(3.97,7.93)\end{array}$ & $\begin{array}{c}1 \\
(1,3)\end{array}$ & $\begin{array}{c}70 \\
(47,94)\end{array}$ & $\begin{array}{c}0.11 \\
(0.11,0.32)\end{array}$ & $\begin{array}{c}1.47 \\
(0.99,1.98)\end{array}$ \\
\hline 6 Insites -24 Hours & $\begin{array}{c}5.34 \\
(3.56,7.12)\end{array}$ & $\begin{array}{c}2 \\
(1,2)\end{array}$ & $\begin{array}{c}72 \\
(48,96)\end{array}$ & $\begin{array}{c}0.21 \\
(0.11,0.21)\end{array}$ & $\begin{array}{c}1.26 \\
(0.84,1.68)\end{array}$ \\
\hline 7 Insites -24 Hours & $\begin{array}{c}4.73 \\
(3.15,6.31)\end{array}$ & $\begin{array}{c}2 \\
(1,3)\end{array}$ & $\begin{array}{c}74 \\
(49,99)\end{array}$ & $\begin{array}{c}0.21 \\
(0.11,0.32)\end{array}$ & $\begin{array}{c}1.11 \\
(0.74,1.49)\end{array}$ \\
\hline 8 Insites -24 Hours & $\begin{array}{c}4.12 \\
(2.75,5.49)\end{array}$ & $\begin{array}{c}2 \\
(1,2)\end{array}$ & $\begin{array}{c}76 \\
(50,101)\end{array}$ & $\begin{array}{c}0.21 \\
(0.11,0.21)\end{array}$ & $\begin{array}{c}1.00 \\
(0.66,1.33)\end{array}$ \\
\hline 9 Insites -24 Hours & $\begin{array}{c}3.51 \\
(2.34,4.68)\end{array}$ & $\begin{array}{c}1 \\
(2,2)\end{array}$ & $\begin{array}{c}77 \\
(52,103)\end{array}$ & $\begin{array}{c}0.11 \\
(0.21,0.21)\end{array}$ & $\begin{array}{c}0.90 \\
(0.61,1.20)\end{array}$ \\
\hline 10 Insites -24 Hours & $\begin{array}{c}2.91 \\
(1.93,3.87)\end{array}$ & $\begin{array}{c}2 \\
(1,3)\end{array}$ & $\begin{array}{c}79 \\
(53,106)\end{array}$ & $\begin{array}{c}0.21 \\
(0.11,0.32)\end{array}$ & $\begin{array}{c}0.83 \\
(0.56,1.12)\end{array}$ \\
\hline 11 Insites - 24 Hours & $\begin{array}{c}2.29 \\
(1.53,3.06)\end{array}$ & $\begin{array}{c}2 \\
(1,2)\end{array}$ & $\begin{array}{c}81 \\
(54,108)\end{array}$ & $\begin{array}{c}0.21 \\
(0.11,0.21)\end{array}$ & $\begin{array}{c}0.78 \\
(0.52,1.03)\end{array}$ \\
\hline 12 Insites - 24 Hours & $\begin{array}{c}1.69 \\
(1.12,2.24)\end{array}$ & $\begin{array}{c}2 \\
(1,2)\end{array}$ & $\begin{array}{c}83 \\
(55,110)\end{array}$ & $\begin{array}{c}0.21 \\
(0.11,0.21)\end{array}$ & $\begin{array}{c}0.73 \\
(0.48,0.97)\end{array}$ \\
\hline 13 Insites -24 Hours & $\begin{array}{c}1.08 \\
(0.71,1.43)\end{array}$ & $\begin{array}{c}2 \\
(1,3)\end{array}$ & $\begin{array}{c}85 \\
(56,113)\end{array}$ & $\begin{array}{c}0.21 \\
(0.11,0.32)\end{array}$ & $\begin{array}{c}0.69 \\
(0.45,0.92)\end{array}$ \\
\hline 14 Insites -24 Hours & $\begin{array}{c}0.47 \\
(0.31,0.62)\end{array}$ & $\begin{array}{c}1 \\
(2,2)\end{array}$ & $\begin{array}{c}86 \\
(58,115)\end{array}$ & $\begin{array}{c}0.11 \\
(0.21,0.21)\end{array}$ & $\begin{array}{c}0.65 \\
(0.44,0.86)\end{array}$ \\
\hline 15 Insites -24 Hours & $\begin{array}{c}0.00 \\
(0.00,0.00)\end{array}$ & $\begin{array}{c}2 \\
(0,2)\end{array}$ & $\begin{array}{c}88 \\
(58,117)\end{array}$ & $\begin{array}{c}0.21 \\
(0.00,0.21)\end{array}$ & $\begin{array}{c}0.62 \\
(0.41,0.41)\end{array}$ \\
\hline
\end{tabular}

Note: The numbers in parentheses represent the results of the sensitivity analysis: (20 per cent sharing rate, 40 per cent sharing rate). 